\title{
UCLA
}

InterActions: UCLA Journal of Education and Information Studies

Title

Ask Dr. Chu: An Interview with a Peruvian-born Chinese Canadian Living in the U.S.

Permalink

https://escholarship.org/uc/item/5js6g6g2

Journal

InterActions: UCLA Journal of Education and Information Studies, 3(2)

ISSN

$1548-3320$

Authors

Chancellor, Renate

Chu, Clara M.

Publication Date

2007-07-09

DOI

10.5070/D432000603

Peer reviewed 


\section{Ask Dr. Chu: \\ An Interview with a Peruvian-born Chinese Canadian Living in the U.S.}

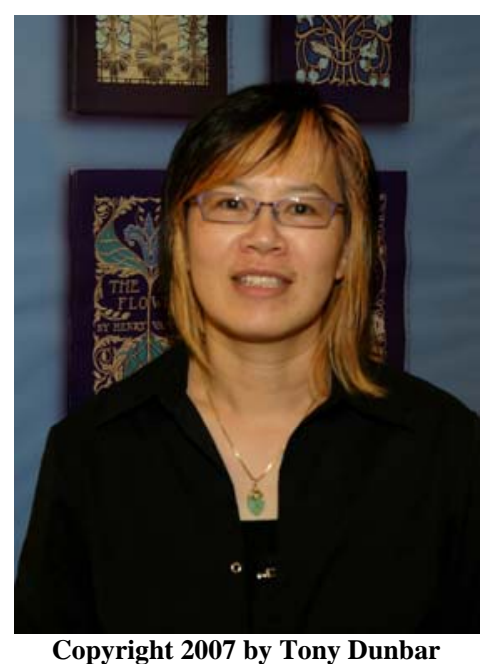

Introduction

Clara Chu is an Associate Professor in the Department of Information Studies at the University of California, Los Angeles. Her research interests include multicultural library and information services, information seeking behavior and critical information studies. Inspired by educator Paulo Freire, Professor Chu's goal is to eradicate the 'culture of silence' created when individuals are oppressed by information practices and systems that deny them access and representation.

As one of the leading scholars on multiculturalism and information practices, Clara has published numerous articles on issues related to diversity, equity and multilingual information resources. In addition to her publications, she has been recognized for outstanding contributions to the library profession. In 2002, the American Library Association honored her with its Equality Award for promoting equality in the profession. And, in 2005 she was noted in Library Journal as a person who is shaping the future of libraries through her innovativeness and eagerness to make a difference. More information can be found about Clara at her website at: http://www.gseis.ucla.edu/faculty/chu .

Renate Chancellor is a Ph.D. candidate in the Department of Information Studies at UCLA. Her research interests include historical research methods and design and the history of librarianship and library education. She is also a book review editor of InterActions: UCLA Journal of Education and Information Studies. 
The following interview with Information Studies professor Clara Chu explores some of the central issues facing immigrant library users. She shares with us some of her life experiences as an immigrant and her views on the current immigration debate as well as its implications for information professionals and library educators.

On June 12, 2007, I had the opportunity to sit with UCLA Information Studies professor, Clara Chu to discuss her views on Immigration...

RC: Clara, let's begin our discussion with telling the readers a little about your early background?

CC: I guess one can find out about my background by the way I describe myself and that is as a Peruvian-born Chinese-Canadian residing in the United States. I was born in Chiclayo, Peru which is in the northern part of the country. I grew up in a household of Chinese immigrants and was there until the age of 10 at which point my family decided to emigrate to Canada where I did my Grades 6-12 and higher education. For one year of graduate studies, 1982-83, I did come to the United States to study in California so I had the opportunity to live here before actually moving to the U.S. because of a job opportunity. To tell you a little more about my background, my parents are from Canton (now Guangzhou), China and after the Second World War and the Communist government taking over the country, my father's family, which was middle class, lost everything, but they had enough contacts and family relationships in other parts of the world so they asked my father to go and make a living overseas so that he could be able to continue to support the family. So, he left to go to Peru first and my mother followed him about eight to nine years later. Because of the different migrations, my family can be situated in three places and this is represented by where the five children were born. My oldest brother was born in China and when my mother moved to Peru to join my father, he was left behind because it was felt that as the oldest son he should have a Chinese upbringing. Once my mother joined my father the three daughters were born - my older sister, myself and my younger sister. When we moved to Canada, my youngest brother was born. So, we have a family of five siblings born in different parts of the world.

RC: What were your first impressions of the United States?

CC: I lived in Vancouver close to the border in Canada and so I had made several trips over to the United States just to visit. From what I recall there were many 
things that were similar to Canada. But I think the perspectives that Canadians have of the United States is very much colored by what we see on television or the media and the extent of the power that the United States has internationally. As a Canadian I always felt like a second cousin or the dwarf next to the giant. So, there was always this sense that culturally we were dominated by the U.S. because we only had one public television channel while all the other channels would be the commercial ones from the U.S. so we would get a lot of news, entertainment and other popular media from the U.S. The other aspect was to see politically how the policies of the U.S. were quite different from those of Canada. And, in terms of one kind of visual impression that one would get when we would come across the border we felt was a result of Affirmative Action policies, that is, whenever we would go into retail stores or banks, there seemed to be certain tokenism where there would be at least one of each racial category and then many Whites represented in the staff, or if it was a service industry then there would be more ethnic minorities. That would be a little different from Canada. Canada, being a country that has a multicultural policy, there is a sense of equity that is addressed within government policy and implemented in the public sector. Instead of using an approach of Affirmative Action to the extent that you ensure that there's one of each and that's it. I think there's more of a sense that if the right people qualify, those are the ones that would be hired, keeping in mind that one wants to diversify any particular organization or company.

\section{RC: How did you come to be interested in Library and Information Science (LIS)?}

CC: I became interested because as an immigrant, my first encounter in Canada with places I wanted to go to were, one the park where I was able to meet a lot of people and have a lot of fun, socializing and playing. This was at the age of 10 . The second, it was amazing to discover when we moved into Chinatown in Vancouver and lived half a block from an elementary school that there would be a bookmobile that would come every week. It was such an exciting thing to go to a bookmobile - an actual transportation mechanism that had books in it and the possibility of going in and borrowing books freely and even though I didn't know how to read and write in English, I was able to go into this bookmobile and be able to take out books. So my approach was that I would be borrowing books at the age of ten, but at the level of a beginning reader. I was able to learn a lot about children's literature of North America even at the age of 10 because I started out reading the easy books and worked my way up. So I found that at the beginning the bookmobile as a library was accessible in terms of providing the resources to be able to learn the language of my new adopted country and be able to integrate into society and into the educational system. Being an immigrant, we really didn't have too many books at home or any materials to help us with homework, so the 
public library became a place to be able to obtain a lot of the resources to do our homework. So I had always known it as a place where I found not only reading materials but other types of information to either assist me with my educational endeavors or just to be able to learn or gather information about certain things.

Library and Information Science wasn't my first priority. I had thought that I wanted to enter a career that would be higher profile. Knowing various languages I wanted to work at the United Nations, so my first master's program of studies was in translation and interpretation. However, I soon found out that knowing languages wasn't enough to be a successful translator/interpreter. At that point I switched gears and was able to reflect on what was it I really enjoyed in my past and that was rediscovering libraries and knowing the place of libraries in my life and in the lives of many people who were like me that were able to get access to free reading and other informational materials. In terms of identifying multicultural and library and information science as a specialization area, it wasn't a consideration when I entered my MLS program because it wasn't something that was covered initially in the curriculum. For me, that had always been an area that I knew was important. However, because it was not covered in the curriculum I wasn't introduced to the topic until either late in the program or while in the Ph.D. program when a multicultural course was offered as an elective. I not only enjoyed the course a lot but my professor, Hans SchulteAlbert, provide me the opportunity to participate in the development of "Guidelines for Multicultural Library Services" for the Canadian Library Association. That was very interesting and rewarding. However, I just thought that was an important aspect of providing professional service so when it came time for me to decide on a doctoral research topic, this area wasn't even in my radar because the only focus I had seen on multicultural librarianship was this one elective course and not something I had seen much research on. My emphasis was to still focus on people because I've always thought that information empowers people so I wanted to work in the area of information seeking behavior and how it is that people access and find information to address their own needs. I again reflected on the areas of interests I had coming from an undergraduate major in Spanish literature so I decided to examine the information seeking behavior of literary critics and it wasn't until I was about done with my proposal that someone informed my dissertation chair about my community work with ethnic groups, both the Chinese and Latin American ones in the city I was residing in, London, Ontario. My dissertation chair asked me why I wasn't pursuing dissertation research on the information needs of immigrants or ethnic women and I said that it had never occurred to me that this would be an area of research to pursue and she said, "no, no, no, it's actually appropriate and a much needed area." She asked me to think it through and to consider it as my dissertation topic and after 
much consideration I decided I was too far along with my dissertation proposal that I decided I would stick to my original topic and would start this new line of research upon graduation. My first and only tenure-track faculty job was at UCLA and it is in this culturally diverse university and city that I pursued my research on multicultural library and information practices. As is often with marginalized or oppressed groups, research about or by them is invisible in the research literature but according to my chair it was an area that was much needed. Fortunately her validation validated my own thinking about the importance of this research, and once I switched gears, there has been no going back.

RC: As a leading scholar in multicultural and information services what are your thoughts on the current immigration debate?

CC: As an immigrant myself and a member of a group that was desired and shunned at the same time, the current "immigration debate and problem" as some might call it does need to be addressed and addressed in a way where our nation is clear about its policies and to implement them fairly without preference for some groups versus others. I think it's disingenuous when some groups are desired for their cheap and manual labor but not for themselves as individuals and themselves as equal participants in society. It is inhumane to be give entrée to only part of this society whereby we might invite non-nationals in legally to work as temporary workers and then have them leave or in the absence of such policy, then to avert our eyes so that we don't recognize that we are the cause of our own illegal immigration problem by tapping into a source of cheap labor, illegal immigrant workers. As a Chinese American I can look at our history and see that the Chinese were also desired for their cheap labor to build the transcontinental railroad and the historical record, through photographs, shows that when the last spike was nailed to celebrate the transcontinental railroad being opened and completed, there was not a single Chinese American in sight. So, who is desired and who is shunned is a critical issue for us to not only recognize, but also to challenge. My approach to our globalized society is to that we need to think of ourselves as countries that need to be able to engage and share resources and the fact that I had the opportunity to be an immigrant I would like that same opportunity to be available to others. And, that there should be criteria that are fair and to consider the many contributions that immigrants have given, not to look at them as pariahs and not to look at them as taking away resources because history has shown that immigrants have contributed to building this nation and furthermore, there are indigenous groups who have been here even longer and their rights have been taken. So, when we look at the immigrant situation we need to look at our country as a multicultural society and to be able to ensure the rights that were taken away from the native peoples in the United States, that 
those be reinstated and respected and that immigrants also have fair policies that will enable them to come to this country, without any undue bias based on race, ethnicity, nationality, class, gender, sexual orientation, etc.

RC: Does the current infrastructure in place support immigrants having access to resources such as technology?

CC: Yes, public libraries are a great resource for access to computers and the Internet. One of the things they could improve on is the number of computers that would be available but they are available and users just have to be patient in terms of taking their turn to access them. So, in terms of access I think public libraries have been playing a strong role. However, in terms of other aspects of the digital divide, computers for someone who is educated is a little bit easier to use, but for somebody who might not be as educated, for example, someone who has limited English fluency, it would be more difficult. Currently public libraries provide access to the Internet and computers through the default languages that are available on popular browsers, but they provide limited access in non-Roman languages. If one wanted to access the computer in non-Roman languages to access the Internet or search for library materials, few libraries nationally, academic or public, would be able to provide support such a need.

So, there's the problem of language in terms of use and knowing how to use the computer, i.e., the technical skills. Another aspect of the digital divide is whether the content is there to enable someone who wants to use the Internet and the computers. For example, my mother who was always interested in cooking and of course taking care of herself by reading health information, one of the ways I could have helped her with was to maneuver through the Internet, but free consumer health content in Chinese is still very limited. Although I don't have Chinese literacy skills, I'm able to speak it but not read or write it, I would have been able to assist her in by linking to Chinese characters presented as images which she would point to, rather than to have to type in Chinese characters. Also information about local events and other types of activities would be helpful and allow her to interact with the larger local community.

\section{RC: How can library services be improved to support linguistic minorities?}

CC: In terms of providing services to linguistic minorities it is always hard for public librarians who are not multilingual to know what language a particular patron is using. So, if there could be staff who are multilingual and signs that are multilingual which would indicate to the user that services in their language might be available or that they could point to certain phrases that could be translated into 
English to let the librarian know what their particular needs were. We need to be able to work with community partners to see what types of programs we could implement in the respective language of users and as needed, to have community members to assist in these efforts. However, one type of policy that would be very helpful for libraries to have, especially public libraries is what the city of Monterey Park, California has which is "first language access." The policy of the city government of Monterey Park is to provide government services in the first language of the residents of the city. And, the primary languages that are widely spoken are Chinese, Vietnamese, Spanish and English. So, if you call up the city of Monterey Park, use its website, or obtain services in person, then information and communication are available in these languages. Consequently, this particular policy is implemented at the level of public (municipal) library services, so in the city of Monterey Park, you will find signage in these various languages and individuals who can provide services in these languages.

RC: What are some of the systemic challenges that impede immigrants from becoming more literate?

CC: There are many immigrants who don’t have English as their first language, so for those, it would enhance their opportunities to engage in this country as well as to obtain better jobs if they became more literate in English. I think that is always anybody's goal to be able to do that. However, there are barriers because when someone is trying to work to sustain their family and they find very little time to do anything else but work and take care of family responsibilities, then there's very little time to study and learn English. The case of my mother, and this is her experience in Canada, is that of a mother whose primary responsibility was taking care of her children and home and could potentially have pursued learning English. However, as a woman born in China where she did not have access to much education, the educational system was very foreign to her and so there would have been a psychological and emotional barrier for her to have approached an educational program to be able to learn English. So the very few English words that she was able to learn were the ones that she needed to be able to ensure that certain transactions took place. For example, she learned how to answer the phone and had sufficient visual literacy and numeracy to allow her to take public transportation to get to certain locales to shop and to visit family or friends. But beyond those basic needs, she did not pursue English classes and a lot of the barriers are both systemic as well as cultural. To be able to reach someone like my mother then there would need to be outreach programs that would explain to her that going to school would have been a comfortable experience for her, that there was no particular expectation that she performed one way or another and that she was there to learn and others were there to also learn with her. 
RC: Your publication on "Immigrant Children Mediators (ICM): Bridging the Literacy Gap in Immigrant Communities" falls under the rubric of information needs of immigrant children and their parents. Please discuss the findings of your study and the implications for practitioners and researchers in Library and Information Science?

CC: As we know, many families have children who easily learn the language of the newly adopted country while the parents as we spoke earlier may have challenges because they are busy working and it takes them a while longer to be able to learn the language of their adopted country and in this case English. So there is a reliance on their children to act a mediators and children from any age of five on up will be bridging that linguistic and cultural gap for their parents, where their parents may ask them to come along to be able to obtain services and the children would either be helping with interpretation from one language to another or be able to provide cultural cues/context, such as telling, for example, a doctor that in their parent's culture it's best if the patient is treated/addressed in a particular manner. The reliance on these mediators by adults, either parents or other family members or friends, is quite heavy and even though facilitation occurs, it places a great burden on children. And so if social services, or cultural and information services, such as public libraries, could help to reduce such a strong reliance on immigrant children mediators, it would be helpful and permit them to focus on just the task of growing up. On the one hand, to be able to have them there to enhance communication and ensure that the adults have services is great but if the library could find alternatives, this would be even better. The mediators, we found for the most part that they wanted to help out their family members and friends because they knew that without their help there would be limited access to certain resources and services, and many felt that their parents had sacrificed so much for them, that this was the least they could do.

The mediators themselves accessed information by looking up things in the telephone book and obtaining information from their peers and friends, and only after going through certain more accessible resources would they go to the public library. They saw public libraries, schools or institutions as being a bit slower in responding, thus, if they needed access to a lawyer, they would first use the telephone book rather than the public library. Recognizing that the public library may not be the first access point then they need to rethink how they can make information within easy reach of their patrons. For example, placing relevant information on the Internet or promoting phone and virtual reference could be readily implemented. Young people these days are fluent in using the Internet and if certain types of ready reference sources or referral types of information are 
made available through the public library, it would be very helpful to address the needs that immigrant children mediators have.

RC: What is the downside of children taking a leading role in ensuring that their parents obtain the information they need?

CC: Even though the children can be helpful to ensure that the communication happens between adults, if the information being discussed is truly of an adult or serious nature, the child should not be put in a position to have to discuss things that would not be age appropriate, such as financial burdens and illnesses. If they are needed to be handled by the children then they should be a source of last resort. But if there are ways that we can have adult speaking to adult by using telephone accessible multilingual translation services, hiring multilingual staff or providing staff with language learning opportunities. Anytime adult-to-adult communication can take place for adult responsibilities the healthier it will be for all concerned.

RC: How important do you feel is it to have institutions and individuals who work in these institutions reflect the demographics of communities?

CC: I think in any sector of society we should have a diversity of representation. That shows that not only is our society equitable in how it implements policies and provides access to the diversity of opportunities that people can actually obtain. It's important to have an open society and a just society. Secondarily, by having a diverse staff, people who may not be that familiar with libraries would want to come in because they see that people like them are welcome, and they would feel comfortable coming in and talking with someone that they feel shares their same background and potentially language. Additionally, whatever background one has, staff learning more languages is another way to reflect and support a community's linguistic diversity. That's a part of diversity that should be also represented, diversity that goes beyond racial representation, to include linguistic, class, gender and sexual representation, among other cultural characteristics. We need to move towards a composition in society where we have individuals of any background work in a particular environment where we are serving the needs of all so we don't default to African American librarians only serving a predominantly African American community. We need to be able to become a society where we're here for each other, where we have a diversity of staff to represent the diversity of people.

$R C$ : Speaking of diversity, do you feel that diversity in other states is different than in California? 
CC: In terms of thinking about providing information services and training individuals to do so, the challenge that the United States has is that diversity across the country is regional with a distinct set of characteristics. For example, here in California we have a diversity of people but there is more of an emphasis on serving individuals based on their racial than ethnic background. In places like the Midwest and the east coast there is an emphasis on ethnicity, including recognizing the different European ethnic groups so you will find communities that maybe have strong German, Italian, or Portuguese background population and these communities would also be recognized for their richness contributing to the ethnic make up of that particular city or region. So, we need to examine and define diversity broadly to also address other aspects of diversity such as: gender, class, sexual orientation, disability and so forth. Any particular group has diversity within it and if we focus too much on only one aspect and forget about others then we're not going to be able to serve people well based on their particular needs. If we take a particular group such as senior citizens, well, senior citizens don't have all the same needs because there would be variations, one is an immigrant, one speaks English fluently, one has only elementary education in Korean, one is homeless, etc. If we can't keep updated on community demographics, we need to engage in community partnerships so we will be updated on the developments of a particular community and changes taking place; this would be gold for the library. These are ways that we can keep current without having to do major surveys. If we're continuously engaging with community partners, we'll keep current with local developments and be able to anticipate immigrants’ or day laborers’ needs, for example.

RC: On a concluding note I would like to get your comments about ethical obligations for information professionals and educators of Information Studies. Given that the profession is founded on the core principles of democracy, should the profession as a whole take a political stand on immigration rights or should such issues be left to policy-makers?

CC: I think that all the different professional organizations and LIS education programs should recognize that immigrants do contribute to our society and all societies, and the fact that there are illegal immigrants has to be tackled not only by our government but all institutions. Immigrants as a whole do not relish leaving their countries to go to another one where they will either be unwelcomed or mistreated. Abandoning one's home is often a result of a need to seek a better life and for survival, and is not a decision taken lightly and entails a lot of hardship. Oftentimes, immigrants will face danger, be separated from families and friends, experience financial setbacks, face under-employment, and endure 
loneliness, culture shock, and communication problems. The argument has been made that migration is a choice, but it is a choice between a harsh existence and the hope of a better life. I think most of us would take the latter, but how many of us would be courageous enough to face the struggles and risks of an uncertain future that many immigrants face. As a global citizen, I believe our world's resources should be shared and it is the responsibility of all of us to find ways to build bridges of opportunities, respect, and justice, and to erase the boundaries between the (information) rich and poor.

Now going back to the issue of professional ethical obligation. Most of our information professions have associations that recognize equal information services for all and to not distinguish. So, if that's the case then we don't need to ask someone about their residency status, we only need to know what their information needs are and how to address them. If there are particular cases where it's a private archive or library, then whoever is a member would get those services, but if for public institutions the focus should be on serving the public that is in front of us and not be engaged in the work of our government which is to determine who is or who is not legal. National ethnic library associations, such as REFORMA, the National Association to Promote Library and Information Services to Latinos and the Spanish-Speaking http://www.reforma.org/, have been at the forefront in addressing immigrant rights and urging the American Library Association (ALA) to also take an advocacy position. They composed a resolution and presented it to ALA Council which at its Midwinter Meeting on January 22, 2007, adopted the Resolution in Support of Immigrant Rights. The ALA is an organization that has a membership of over 64,000 strong and has a lobbying body in Washington, DC that can tackle these issues, emphasizing its membership, which provides information access to all. As professional associations we often think that we should be neutral in the way we provide information services but information and knowledge has the possibility to empower or dis-empower anyone, so, recognizing that, whatever we can do to ensure and be advocates for the equal access and respectful treatment of individuals is important.

RC: Clara, thank you for taking time and for participating in this thoughtful and engaging discussion. I look forward to continuing this discussion in the future.

CC: Thank you. 


\section{Notes}

${ }^{1}$ Clara M. Chu, "Immigrant Children Mediators (ICM): Bridging the Literacy Gap in Immigrant Communities," Proceedings of the 65th General Conference of the International Federation of Library Associations and Institutions, 20-28th August 1999, Bangkok, Thailand.

http://www.ifla.org/IV/ifla65/papers/109-145e.htm . Also published as a French translation "Enfants immigrés et médiation: une façon de réduire le fossé linguistique pour les communautés immigrées." http://www.ifla.org/IV/ifla65/papers/109-145f.htm 